\title{
Brazilian Pediatric Risk of Severity Model for Illness (BrPRISM)
}

\author{
Mangia CMF MD, MSc, MBA, $\mathrm{PhD}^{1^{*}}$, Nakano EY MSc ${ }^{2}$, Andrade MC MD, MSc, $\mathrm{PhD}^{3}$
}

\author{
${ }^{1}$ Pediatric Critical Care Division, Escola Paulista de Medicina, Universidade Federal de São Paulo, Brazil \\ ${ }^{2}$ Statistics Department, Universidade de Brasília, Brazil \\ ${ }^{3}$ Pediatric Nephrology Division, Escola Paulista de Medicina, Universidade Federal de São Paulo, Brazil
}

DOI: $\underline{10.36347 / \text { sasjm.2020.v06i08.004 }}$

| Received: 30.07 .2020 | Accepted: 07.08.2020 | Published: 24.08.2020

*Corresponding author: Cristina Malzoni Ferreira Mangia

Abstract

Original Research Article

Introduction: The best prognosis score with which to evaluate high-risk patients upon admission into pediatric intensive care is not well established in resource-limited settings. The objective of study was to formulate a risk-ofillness severity model for pediatric mortality to be applied upon PICU admission in resource-limited settings. Methods: Our study was designed to develop an illness severity index and a prognostic model for critically ill children. A prospective, observational multicenter pilot study, performed between February 1995 and October 1999, evaluated the variables, methodology and statistical techniques for the development of a model. A single-center prospective cohort study, performed between November 1999 and October 2004, collected information from consecutive admissions into the Pediatric Intensive Care Unit (PICU) at a high-complexity university, teaching, and reference hospital in São Paulo, Brazil. Results: In the pilot study, 1,459 patients (a PICU mortality rate of $16 \%$ ) were included, and in the second study, 1,033 patients (a PICU mortality rate of $13.9 \%$ and a hospital mortality rate of $6.9 \%$ after PICU discharge) were included. We used multivariable regression to determine two probabilistic models; the first addressed survival and the overall probability of death (hospital plus PICU deaths), and the second was conditional (i.e., PICU death). An illness severity index stratified these probabilities into three risk strata: low-, medium- and highrisk patients. In the final step, the new death probabilities were estimated using a Bayesian adjustment. Conclusions: The model estimates three probabilities (survival, death in the PICU and death in the hospital after PICU discharge) stratified into three risk categories. To the best of our knowledge, this is the first study using a Bayesian adjustment to determine a prognosis and illness severity, and it should enable us to make therapeutic adjustments and provide appropriate counseling for high-risk patients in resource-limited settings.

Keywords: Pediatric, Severity Model, Pediatric Intensive Care Unit (PICU).

Copyright @ 2020: This is an open-access article distributed under the terms of the Creative Commons Attribution license which permits unrestricted use, distribution, and reproduction in any medium for non-commercial use (NonCommercial, or CC-BY-NC) provided the original author and source are credited.

\section{INTRODUCTION}

Prognostication efforts are important steps towards understanding the effects of diseases, medical interventions, and healthcare policies as determinants of outcomes. Mortality risk models enable the evaluation of the healthcare system, management capacity and quality of care and facilitate evidence-based decisionmaking and better resource allocation [1-3].

The outcome in intensive care depends on several factors associated with the patient in the first 24 hours after admission and the disease course during the intensive-care stay. Severity scores are usually comprised of two parts: a severity score, which is a number (in general, a high score reflects a more severe condition), and a probability model, which is an equation that expresses the probability of death in the hospital or intensive care unit (ICU) [3-5].
No consensus about the classification of score systems to be used in the ICU has been reached; they could be used once or repeatedly over time. There are numerous examples of score systems, but the main systems are scores based on abnormalities in the physiological variables measured in the first 24 hours (APACHE, PRISM, PIM) or organ-specific scoring, in which the main prognostic factors are the number and duration of multiple-organ failures (SOFA, PELOD).

The Brazilian healthcare system is a predominantly public enterprise with universal access for all citizens. Over the past few years, as part of the Millennium Development Goals for the reduction of child mortality, new pediatric intensive care units (PICUs) like those in other areas of the world [6] have been introduced. In 1998, the Brazilian Ministry of Health suggested using the Pediatric Risk of Mortality (PRISM) [7] score to assess the severity of illnesses and 
mortality risks and evaluate PICU performance. Studies have reported that this score is not suited for critically ill children in resource-limited settings [8], and it is well recognized that performance scores are variable because the case mix, therapy and selection of patients admitted into the PICU differ over time. Indeed, PRISM has been outdated for more than 10 years and, consequently, is obsolete [1, 3-5].

Our main objective was to formulate a risk-ofillness severity model for pediatric mortality to be applied upon PICU admission in resource-limited settings [3].

\section{METHODS}

The Brazilian Pediatric Risk of Severity Model for Illness (BrPRISM) study was developed in two steps. The first study was a prospective, multicenter, 2 teaching hospitals and 1 private hospital), cohort study performed between February 1995 and October 1999 and included 1,450 patients. This study evaluated the variables, methodology, and viability of performing a multicenter study in Brazil and the statistical techniques required for developing a scoring system and probability model. The second, a validation study, was a single-center; prospective, observational cohort study performed between November 1999 and October 2004 and included 1,100 consecutive patients admitted into | the Hospital São Paulo from_Universidade Federal de São Paulo, Brazil. Hospital São Paulo, a resource for five million inhabitants, is a high-complexity hospital affiliated with the university teaching medical school. The hospital has 700 beds ( 80 pediatric) and receives 530,000 emergencies, 32,264 admissions and 163,305 surgeries per year. The pediatric intensive care unit (PICU) has 8 beds and admits medical and surgical patients between the ages of 0 and 19 years. In the study period, we had 16 pediatric intensive care residents each year. The medical staff included 2 physicians during the day, 1 physician at night and a total staff of 18 pediatric intensivists (including weekends). In addition, the nurse-to-patient ratio was 1 nurse to each of 3 beds and one physiotherapist to 8 beds.

Sample selection: All of the consecutive admissions of patients under the age of 19 were analyzed, except the following: a) patients with a PICU stay of less than 24 hours; b) patients admitted while receiving continuous cardiopulmonary resuscitation without stable signs for at least 2 hours; c) brain-dead patients admitted for organ donation. For those patients with multiple PICU admissions during the same hospital stay, only the data from the first admission were analyzed. Re-admissions were analyzed if they occurred more than 30 days after PICU discharge. To determine the outcome, the patients were followed up until they were discharged from the hospital. Any patients remaining in the hospital after October 31, 2004, were excluded from the study because their status could not be assessed. The study was approved by the institutional ethics committee, and parental consent was obtained in all cases.

Variable selection: The variables were selected based on our past experience with first study, clinical judgment, interviews with the intensivists and score review and considered a wide range of citations on the literature, such as the Pediatric Risk of Mortality II [7] and III [9], the Acute Physiology, Age, and Chronic Health Evaluation III [10], the Simplified Acute Physiology Score II [11], Mortality Probability Models II [12], the Pediatric Index of Mortality [13] and the Acute Physiology, Age, Chronic Health Evaluation II [14]. All the data were collected by the main investigator.

The physiological variables that were eligible for analysis are as follows: the systolic blood pressure, the heart rate, the respiratory rate, the axillary temperature, any pupillary reactions, the coma status, diuresis, arterial gasometry, the $\mathrm{PaO}_{2} / \mathrm{FiO}_{2}$ ratio, glucose, potassium, sodium, creatinine, urea, hemoglobin, hematocrit, platelet count, the white blood cell count, and the prothrombin and activated partial thromboplastin times. The other, non-physiological, variables are as follows: age, age group, gender, the inhospital location before PICU admission, any comorbidities, the clinical or surgical status, the diagnosis by system and etiology (during the first 24 hours), the use of vasoactive drugs, the use of external oxygen or mechanical ventilation, the length of stay (LOS) before and after the PICU, the PICU LOS, the total length of the hospital stay and any outcome data (the vital status in the PICU and upon hospital discharge) [13-18].

The physiological variables were collected upon admission, and, if the laboratory had missed any biochemical data, we recorded the worst value achieved in the first 24 hours according to the strict definitions of the previously established variables (Appendix 1). When these values were age-dependent, we used the range limits of the normal physiological values by age group.

We developed a comprehensive instruction manual, which described all the procedures that led to the data collection and definition. This manual was based on the evidence in the literature and included a full description of the study and strict definitions of the variables, their codes, and, when applicable, their units and normal ranges according to the age group. The age group was based on the recommendations of the Ministry of Health, which established the following risk-specific age groups for Brazilian children: less than 12 months, between 12 and 59 months, between 60 and 119 months, between 120 and 179 months and between 180 and 228 months [19]. 
The data were collected in a clinical report form (CRF), the variables were codified, and the internal quality of the data was checked before keyboarding into the $\mathrm{ACCESS}^{\circledR}$ database that was specially created for this study. The program checked for any out-of-range data using a logical error system and compiled a report regarding any inconsistent data for each patient. The quality control of the database included double-keyboarding by two trained and independent physicians. The first and second sets of keyboarding were compared to the CRF to determine the reliability of the data from the first and second procedures. The reliability of the data was compared to that of the CRF and the medical record. To determine the diagnostic category after PICU admission, we developed a list of the ten major categories of clinical diseases and nine major categories of surgical interventions. For each major category, we developed a list of 124 etiology classes according to the age group and the epidemiology of the pediatric diseases $[9,11$, 12]. The same procedure was used for the categorization of the comorbidities [15].

\section{STATISTICAL ANALYSIS}

The demographic data were represented as absolute numbers and percentages, and the continuous variables were represented as medians and interquartile ranges. A p-value of less than 0.05 was significant.

We used multivariable regression to determine two probabilistic models; the first addressed the probability of death in the PICU, and the second was conditional (i.e., the probability of death in the hospital after the PICU stay) [20-22].

We eliminated variables from the models by backward deletion. These two models produced a of probabilities for each patient. The first element focuses on hospital survival, the second focuses on death in the hospital after PICU discharge, and the third probability focuses on the death probability during the PICU stay. Based on these three probabilities, we created a severity index that stratifies patients from the worst (PICU death) to best (hospital survival) outcomes according to a previously published method $[23,24]$. The a priori probabilities of model were: $10 \%$ (death in the PICU), $5 \%$ (death in the hospital after PICU stay) and $85 \%$ (hospital survival) [23, 24]. As a final step, the Bayesian method was applied to estimate the new adjustment of probabilities (a posteriori) using the severity index. Statistical analysis was performed using SPSS (version 11.0) and Excel 2000.

\section{RESULTS}

The variables were collected from 1,100 patients, 67 patients were excluded (37 patients were discharged within 24 hours after PICU admission, 2 patients were still hospitalized at the end of the study, 17 patients died within the first 24 hours after PICU admission, and 11 patients were admitted into the PICU

for organ donation after brain death). Following the exclusions, 1,033 patients were included in the development of the model. The patients' characteristics are summarized in Table 1. Comorbidities were present in $73.9 \%$ of the patients. The main comorbidities were as follows: congenital cardiac disease $(21.2 \%)$, chronic neurological disease $(10.6 \%)$, chronic renal disease (7.6\%) and chronic pulmonary disease $(6.2 \%)$.

Table 2 presents the logarithm of the first regression analysis, and Table 3 presents the log of the second regression analysis.

The severity index (SI) was calculated using the following equation: $\mathrm{SI}=\left(2^{1 / 2}+1\right) \operatorname{Pr}(\mathrm{U})-\left(2^{1 / 2}\right) \operatorname{Pr}(\mathrm{H})$, where $\operatorname{Pr}(\mathrm{U})$ is the probability of dying in the PICU, and $\operatorname{Pr}(\mathrm{H})$ is probability of dying in the hospital after the PICU stay (table 4 ). The cutoff value was $\leq 0.15$ for the SI of the survivors, 0.16 to 0.30 for hospital mortality after the PICU stay, and $\geq 0.30$ for PICU mortality. Next, we re-adjusted the probabilities using 3 severity classes based on the cutoff points of the index (high, medium, or low probability of death). The index demonstrated good differentiation among the 3 severity classes $(\mathrm{p}<0.001)$. The area under the ROC curve (AUC) for the survivors (index $\leq 0.15$ ) was good $(0.821 ; 95 \%$ CI, $0,789-0,854)$. The cutoff point was 0.1564 (sensitivity, 0.738; 1-specificity, 0.265). The Hosmer-Lemeshow goodness-of-fit chi-squared value for the survivors was 22.154 with 8 degrees of freedom $(\mathrm{p}=0.005)$.

The AUC for death in the PICU (index $\geq 0.30$ ) was good $(0.746 ; 95 \% \mathrm{CI}, 0,676-0,817)$. The cutoff point was 0.3058 (sensitivity, 0.674; 1-specificity, 0.324). The Hosmer-Lemeshow goodness-of-fit chisquared value for the deaths in the PICU was 9.300 with 8 degrees of freedom ( $\mathrm{p}=0.318)$. The a posteriori probabilities for each diagnostic category (hospital survival, patient death in the hospital after the PICU stay and patient death during the PICU stay) and the risk strata are presented in Table 5.

BrPRISM compared to PIM and PIM 2: We compared the performance of BrPRISM to two scores with free access in the literature. The Pediatric Index of Mortality (PIM; versions 1 and 2) met this criterion. The PIM and PIM 2 scores were collected for 387 patients. The standardized mortality rate (SMR) for the PIM score was 2.464 (95\% CI, $1.413-3.515)$, and the odds ratio was 0.56 (95\% CI, $0.33-0.95)$; the SMR for the PIM 2 score was $2.526(95 \%$ CI, $1.366-3.687)$, and the odds ratio was $0.94(95 \% \mathrm{CI}, 0.57-1.57)$. The area under the ROC curve was 0.882 (95\% CI, 0.846 0.913) for BrPRISM, 0.736 (95\% CI, 0.689 - 0.7790) for PIM and 0.720 (95\% CI, 0.672 - 0.764) for PIM 2. The pairwise comparison of the ROC curves for BrPRISM vs. PIM and PIM2 showed a difference between the area under ROC curve $(0.146 ; 95 \% \mathrm{CI}$, $0.054-0.238 ; p=0.002)$. The areas of BrPRISM vs. 
PIM 2 were different $(0.163 ; 95 \%$, CI $0.066-0.260 ; p=$ 0.001). The areas of PIM vs. PIM 2 were also different
(0.017; 95\% CI $0.044-0.077 ; p=0.591)$.

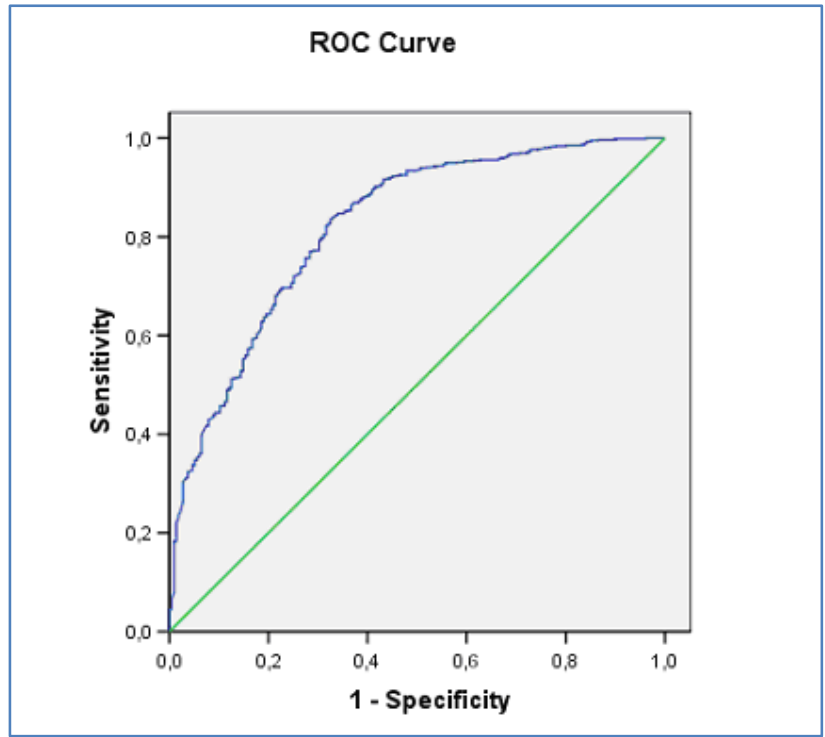

Fig-1: The area under the ROC curve (AUC) for survivors (BrPRISM index $\leq \mathbf{0 . 1 5}$ )

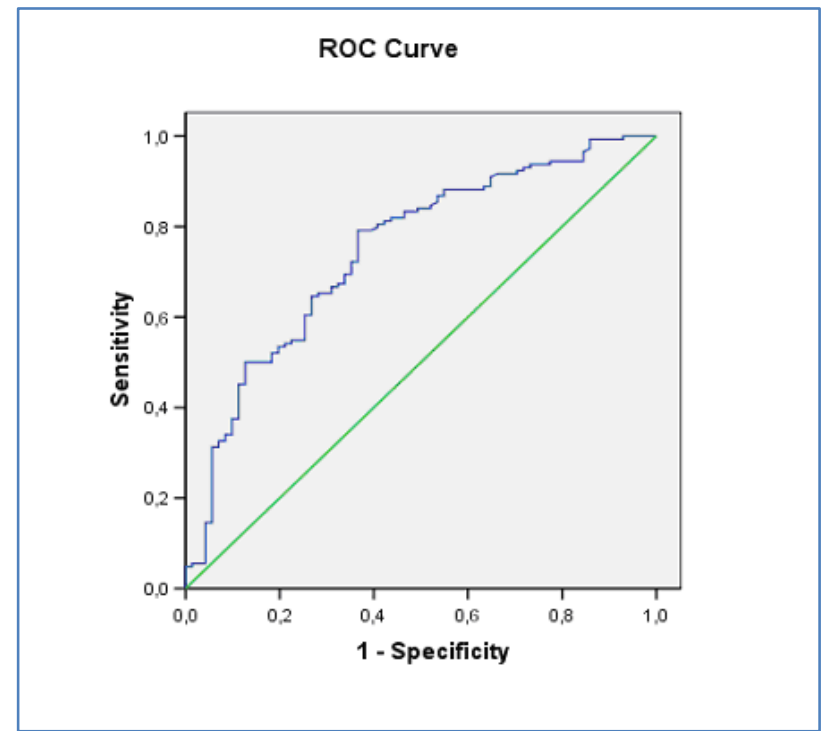

Fig-2: The AUC for death in the PICU (BrPRISM index $\geq 0.30$ )

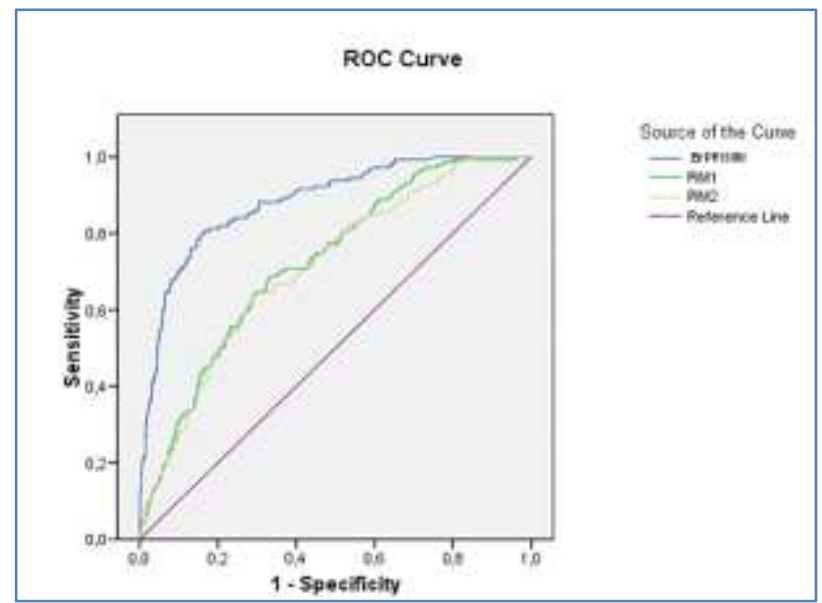

Fig-3: Comparison between ROC curves BrPRISM, PIM and PIM 2 
Table-1: Demographic characteristics of the patients

\begin{tabular}{|c|c|c|}
\hline & $\mathbf{N}$ & Frequency $(\%)$ \\
\hline Number of patients & 1033 & 100 \\
\hline \multicolumn{3}{|l|}{ Gender } \\
\hline Female & 469 & 45.4 \\
\hline Male & 564 & 54.6 \\
\hline \multicolumn{3}{|l|}{ Age group } \\
\hline$<12$ months & 447 & 43.3 \\
\hline $12-60$ months & 331 & 32.0 \\
\hline $60-120$ months & 150 & 14.5 \\
\hline $120-180$ months & 88 & 8.5 \\
\hline $180-228$ months & 17 & 1.6 \\
\hline \multicolumn{3}{|c|}{ Intra-hospital location before PICU admission } \\
\hline Emergency room & 292 & 28.3 \\
\hline Ward & 243 & 23.5 \\
\hline Intermediate care unit & 106 & 10.26 \\
\hline Operating room & 392 & 37.94 \\
\hline \multicolumn{3}{|l|}{ Major Categories of disease } \\
\hline Clinic & 641 & 62.1 \\
\hline Surgical & 392 & 37.9 \\
\hline \multicolumn{3}{|l|}{ Main Clinics Grupo Disease } \\
\hline Sepsis & 190 & 18.4 \\
\hline Cardiovascular & 102 & 9.9 \\
\hline Respiratory & 221 & 21.4 \\
\hline \multicolumn{3}{|l|}{ LOS*, days ( median, Q1 -Q3) $\dagger$} \\
\hline LOS before PICU $\$$ & 2.00 & $0-8$ \\
\hline LOS PICU & 5.00 & $2-9$ \\
\hline LOS after PICU & 9.00 & $3-23$ \\
\hline LOS Hospital & 23.00 & $11-47$ \\
\hline \multicolumn{3}{|l|}{ Outcome } \\
\hline Hospital Survival & 818 & 79.2 \\
\hline \multicolumn{3}{|l|}{ Mortality } \\
\hline PICU mortality & 144 & 13.9 \\
\hline Hospital mortality after PICU & 71 & 6.9 \\
\hline Total mortality & 215 & 20.8 \\
\hline
\end{tabular}

*LOS: length of stay; $\uparrow \mathrm{Q} 1, \mathrm{Q} 3$ : lower and upper interquartile range, respectively; $\$$ PICU: Pediatric intensive care unit

Table-2: Variables for regression 1, the probability of death in the PICU with their estimated coefficients, standard error (SE), Wald statistic, adjusted odds ratio, and $95 \%$ confidence intervals for the adjusted odds ratio

\begin{tabular}{|c|c|c|c|c|c|c|c|c|}
\hline & $\mathbf{B}$ & S.E. & Wald & df & Sig. & $\operatorname{Exp}(B)$ & \multicolumn{2}{|c|}{ 95,0\% C.I. for EXP(B) } \\
\hline & & & & & & & Lower & Upper \\
\hline Medical disease ${ }^{*}$ & 1,057 & ,269 & 15,429 & 1 &, 000 & 2,877 & 1,698 & 4,874 \\
\hline Comorbidities $^{\dagger}$ & 1,179 & 251 & 22,141 & 1 &, 000 & 3,250 & 1,989 & 5,311 \\
\hline Hypotension ${ }^{*}$ &, 569 & 279 & 4,150 & 1 &, 042 & 1,766 & 1,022 & 3,053 \\
\hline Pupil reaction & 2,006 &, 500 & 16,096 & 1 & 000 & 7,431 & 2,789 & 19,795 \\
\hline Metabolic Coma $^{\S}$ &, 774 &, 359 & 4,647 & 1 &, 031 & 2,169 & 1,073 & 4,384 \\
\hline Hypoxemia &, 541 & ,266 & 4,120 & 1 & ,042 & 1,717 & 1,019 & 2,894 \\
\hline Mechanical ventilation $^{\text {पा }}$ & 1,014 & ,286 & 12,593 & 1 &, 000 & 2,757 & 1,575 & 4,828 \\
\hline Coagulopathy $^{* *}$ &, 850 & 240 & 12,489 & 1 & ,000 & 2,339 & 1,460 & 3,747 \\
\hline Hyperglycemia ${ }^{\dagger}$ &, 789 & 245 & 10,399 & 1 & ,001 & 2,201 & 1,363 & 3,555 \\
\hline Hyponatremia & 1,047 & ,291 & 12,913 & 1 & ,000 & 2,848 & 1,609 & 5,040 \\
\hline Vasoactive drugs & 1,059 & ,240 & 19,531 & 1 &, 000 & 2,884 & 1,803 & 4,613 \\
\hline Constant & $-5,603$ & ,436 & 165,364 & 1 &, 000 &, 004 & & \\
\hline
\end{tabular}

$\beta$ : coefficient; SE: standard error; Wald: statistic Wald; Sig: p value ; CI 95\%: confidence interval of $95 \%$. *Medical diseases: non-surgical patients; 'comorbidities: congenital cardiophaties, oncologic diseases, chronic kidney failure, chronic liver failure, genetic syndromes, AIDS; ${ }^{\ddagger}$ systolic blood pressure (SBP): between 0 to 119 months $\leq 70 \mathrm{mmHg}$ and between 120 months to 180 months $\leq 90 \mathrm{mmHg}$. 
pupil reaction: both fixed, miosis bilateral and few reactions, pinpoint and no-reactive, one fixed and one reactive.; ${ }^{\S}$ Glasgow metabolic: Glasgow coma score for metabolic disease $\leq 10 ;$ "Arterial oxygen saturation (Sat $\mathrm{O}_{2}$ ) $<90 \%$; ${ }^{* *}$ APTT: 1.5 fold up to reference value or $>$
$52.5 \mathrm{sec} ;{ }^{\dagger}$ Glucose $\geq 150 \mathrm{mg} / \mathrm{dL} ;{ }^{\dagger}$ Sodium $\leq$ $130 \mathrm{mEq} / \mathrm{L}$; Use of Mechanical ventilation ${ }^{\mathbb{T}}$ and ${ }^{\S \S}$ Vasoactive drugs. †ATTP: Activated partial thromboplastin time.

Table-3: Conditional regression probability probability of death in the hospital after PICU stay and their estimated coefficients, standard error (SE), Wald statistic, adjusted odds ratio, and $95 \%$ confidence intervals for the adjusted odds ratio [EXP(B)]

\begin{tabular}{|c|c|c|c|c|c|c|c|}
\hline & B & S.E. & Wald & Sig. & $\operatorname{Exp}(B)$ & \multicolumn{2}{|c|}{ 95,0\% C.I. for $\operatorname{EXP}(B)$} \\
\hline & & & & & & Lower & Upper \\
\hline Age group $<12$ months ${ }^{*}$ & 1,203 & ,305 & 15,537 &, 000 & 3,330 & 1,831 & 6,056 \\
\hline Comorbidities ${ }^{\dagger}$ & ,648 & ,298 & 4,743 &, 029 & 1,912 & 1,067 & 3,426 \\
\hline LOS before PICU* & 1,660 & ,324 & 26,305 &, 000 & 5,258 & 2,788 & 9,914 \\
\hline Hyperthermia $^{\S}$ &,- 876 &, 350 & 6,255 &, 012 & ,417 &, 210 & ,827 \\
\hline Oliguria &, 873 & ,366 & 5,689 &, 017 & 2,395 & 1,168 & 4,907 \\
\hline Metabolic Coma $^{\text {q }}$ & 1,699 & ,413 & 16,964 &, 000 & 5,469 & 2,437 & 12,277 \\
\hline Coagulopathy /APTT $^{* * *}$ &, 715 & ,302 & 5,610 & ,018 & 2,045 & 1,131 & 3,697 \\
\hline Hypercalemia $^{\dagger \dagger}$ & 1,701 & ,433 & 15,403 &, 000 & 5,477 & 2,343 & 12,804 \\
\hline Constant & $-4,206$ & 370 & 129,219 & ,000 &, 015 & & \\
\hline
\end{tabular}

Hosmer-Lemeshow goodness-of-fit test: $p=0,559 ; X^{2}=6,794$ e $8 \mathrm{gl}$

$\beta$ : coefficient; SE: standard error; Wald: statistic Wald; Sig: p value; CI 95\%: confidence interval of 95\%. "Age group < 12 months; †comorbidities: congenital cardiophaties, oncologic diseases, chronic kidney failure, chronic liver failure, genetic syndromes, AIDS; LOS before $\mathrm{PICU}^{\ddagger} \geq 8$ days;
${ }^{\S}$ Hyperthermia > 38oC; $\|$ Oliguria $\leq 1 \mathrm{ml} / \mathrm{kg} / \mathrm{hr}$; ${ }^{\S}$ Glasgow metabolic: Glasgow coma score for metabolic disease $\leq 10 ;{ }^{* *}$ APTT: 1.5 fold up to reference value or $>52.5 \mathrm{sec} ;{ }^{\dagger}$ Hypercalemia $\geq 6 \mathrm{mEq} / \mathrm{L}$

Table-4: Distribution of patients according to severity index stratum and the area under ROC curve

\begin{tabular}{|l|c|c|c|c|}
\hline \multicolumn{5}{|c|}{ Stratum Classification based in the Severity index and AUC } \\
\hline Diagnosis category & $\begin{array}{c}\text { Survivors } \\
\mathrm{I}^{*} \leq 0.1564 \\
\text { Low Risk }\end{array}$ & $\begin{array}{c}\text { Hospital death } \\
0.1564<\mathrm{I}^{*}<0.3058 \\
\text { Middle Risk }\end{array}$ & $\begin{array}{c}\text { PICU death } \\
\mathrm{I}^{*} \geq 0.3058 \\
\text { High Risk }\end{array}$ & Total (n) \\
\hline Survivors & 604 & 146 & 68 & $\mathbf{8 1 8}$ \\
\hline Hospital death & 34 & 14 & 23 & $\mathbf{7 1}$ \\
\hline PICU death & 23 & 24 & 97 & $\mathbf{1 4 4}$ \\
\hline Total ( n) & $\mathbf{6 6 1}$ & $\mathbf{1 8 4}$ & $\mathbf{1 8 8}$ & $\mathbf{1 0 3 3}$ \\
\hline \multicolumn{7}{|c|}{ *Index $(\mathrm{I})=\left(2^{1 / 2}+1\right) \operatorname{Pr}(\mathrm{U})-\left(2^{1 / 2}\right) \operatorname{Pr}(\mathrm{H})$} \\
\end{tabular}

Table-5: Classification of severity according to its a posteriori probability

\begin{tabular}{|l|c|c|c|c|}
\hline \multicolumn{5}{|c|}{ Index Stratum Classification } \\
\hline \multicolumn{2}{|c|}{} & Low Risk & Middle Risk & High Risk \\
\hline Diagnosis category & a priori & The patient's probabilities after index (a posteriori) \\
\hline Survival & $85 \%$ & $94 \%$ & $85 \%$ & $46 \%$ \\
\hline Hospital death & $5 \%$ & $3.5 \%$ & $5.6 \%$ & $10.5 \%$ \\
\hline PICU death & $10 \%$ & $2.4 \%$ & $9.4 \%$ & $43 \%$ \\
\hline
\end{tabular}

\section{INTERPRETATION}

a) If the patient is classified in the low index stratum, the vital status probabilities for each diagnosis category (Survival; Hospital_death and PICU_death) are improved from $85 \%, 5 \%$ and $10 \%$ (a priori) to $94 \%$; $3.5 \%$ and $2.4 \%$ (posteriori), respectively;

b) If the patient is classified in the middle index stratum, the vital status of probabilities for each diagnosis category (Survival; Hospital_death and
PICU_death) are improved from 85\%, 5\% and 10\% ( a priori) to $85 \% ; 5.6 \%$ and $9.4 \%$ (posteriori), respectively;

c) If the patient is classified in the high index stratum, the vital status of probabilities for each diagnosis category (Survival; Hospital_death and PICU_death) are improved from $85 \%, 5 \%$ and $10 \%$ ( a priori) to $46 \% ; 11 \%$ and $43 \%$ (posteriori), respectively; 


\section{DISCUSSION}

We undertook this study to develop an illness severity index and a prognostic risk model for critically ill children that will be useful and relevant to middleincome environments. This model is based on variables that are easily collected [25] at the bedside and includes well-defined [26] variables that are selected a priori. The investigators collecting the data were blinded to the study objectives, and continuous, rigorous monitoring was done to eliminate the possibility of missing [26, 27] information to guarantee a high-quality database [28].

The laboratory variables were collected upon admission; however, when the sample was lost or when technical problems arose during the processing of the samples by the laboratory, the worst value during the first 24 hours was recorded [9]. We adopted this criterion because, in our practice, the first sample was susceptible to loss (breakdown of the sample bottle, for example), or there was a lack of the reagents with which to process the sample immediately or during sampling [16].

We defined any admission that occurred after thirty days after PICU discharge as a new admission. This admission would most likely be the result of a new clinical indication and, therefore, unlikely to be due to an inappropriately early discharge [29]. Additionally, in our medical practice, mortality in the PICU is an inadequate measure with which to evaluate the outcomes of a critical disease. The inclusion of the hospital mortality after PICU discharge adds a new element to the prediction and improves our knowledge regarding outcomes outside the PICU, which may have a direct bearing on PICU care or the early discharge of unstable patients [29].

By analyzing the regression models, we found that the overall survival depended more strongly on the physiological variables. However, the biochemical abnormalities in the conditional model were determinants of a major risk for dying in the hospital after PICU discharge.

The model supplied a vector of probabilities with three components (survival, PICU death and hospital death after PICU stay). However, simultaneous interpretations of these data were deemed to be too complex to explain to families and healthcare providers. Therefore, the severity index simplifies the information because only one probability is necessary to explain the gravity of each case [30, 31].

The model_described in this study don't need revised by new validation because the inclusion of new patients in the database and the modification of its initial information the model will be auto adjusted. The attraction of the Bayesian model is that it is a dynamic model and superior to the information provided by the previous risk scores.
Comparing BrPRISM to the PIM and PIM 2 scores showed that the PIM and PIM 2 scores overestimated the mortality in the high- and very highrisk bands and underestimated the mortality in mildand low-risk bands. The ROC curve analysis demonstrated that both had low sensitivity and specificity in our population [32]. These observations could be explained by the fact that the PIM and PIM 2 scores have limitations in resource-limited settings. The applicability of scores such as PIM and PIM 2 in our country is difficulted because of flaws in these scores to assessment of the prognostics after PICU stay (like as death in the hospital stay or hospital survival) and by differences of quality of care (including human, technological and economic factors) rendered by PICU in resource limited settings compared to PICU of high income settings where these scores were developed.

Our study has several limitations, including the fact that the final model was based on a single-center study. However, this option gave us control over data entry into the CRF, which ensured data integrity (loss of sample and laboratory errors) and immediate mistake correction. For example, in the pilot multicenter study, we observed that several variables with units different from those that were standardized by the study were included in the database [20].

Another limitation relates to patient admission into the PICU. In resource-limited settings, owing to the high demand for intensive-care beds, patients who should have been admitted into the PICU earlier had stayed in other hospital settings, and, therefore, specific PICU treatments were delayed [8]. In these setting, patients requiring mechanical ventilation and patients after high-risk surgery are priorities. This situation results in the baseline condition upon PICU admission being worse than in high-income settings [32, 33].

Parents also have difficulties on early recognition of the severity of diseases. Additionally, due to socioeconomic reasons, a lack of transport or being transferred from other hospitals, some patients may present late to emergency care [34]. This situation was represented in another study as lead-time bias or the possibility that the patients may have had a higherthan-predicted mortality, which may generate some degree of error during scoring. However, this situation is impossible to control [8]. In addition, the current model refers to a specific population and will need to be used and validated in a new cohort similar to the reference population before it can be used in a largescale setting $[16,35,36]$.

This model is the first pediatric model developed for resource-limited settings such as Brazil. Brazil does not have a prognostic and severity model with which to examine the effect of disease severity on patient admission into the PICU, after PICU stay and 
after Hospital stay. This information would be useful when analyzing the costs (especially PICU and infirmary care costs) to the Unified Health System (SUS) and the relative benefits to society. We believe that the use of this model could improve the training of PICU teams by aiding in the development of the skills necessary to discriminate between the severity categories of diseases, establish early treatment strategies and minimize costs, mortality and sequelae.

\section{CONTRIBUTORS}

Mangia CMF wrote the methodology of this study, drafted study, carried out the cohort study, all data collection, data typewrite, development of all steps of the database software, performed the descriptive and inferential statistical analysis and wrote the manuscript. Nakano EY performed the inferential and Bayesian statistical analysis. Andrade MC contributed with ideas and critical revision, development of all steps of this study. The paper was revised and approved by all contributors.

\section{ACKNOWLEDGEMENTS}

We would kindly like to thank Pereira CAB, $\mathrm{PhD}$ (Bayesian analysis). Ms. Gucoff $\mathrm{C}$ for her valuable work to develop the five versions of the database software and its updates. In addition, we would kindly like to thank de Carvalho WB for his indispensable permission for the accomplishment of this study in the PICU and to colleagues of all centers of pilot study.

\section{Conflict of interest statement} of interests

The authors declare that they have no conflict

\section{REFERENCES}

1. Wasson JH, Sox HC, Neff RK, Goldman L. Clinical prediction rules: applications and methodological standards. New England Journal of Medicine. 1985 Sep 26;313(13):793-9.

2. Logan RL, Scott PJ. Uncertainty in clinical practice: implications for quality and costs of health care. The Lancet. 1996 Mar 2;347(9001):595-8.

3. Mangia, CMF. Carvalho WB and Kopelman, BI. Brazilian Pediatric Prognostic Model for Critical Illness. In: 5 th World Congress on Pediatric Critical Care, June 24-28, 2007, Geneve. Ped Crit Care. 2007; 8: A194.

4. Mangia, CMF, Kopelman, BI. Performance of Pediatric Index of Mortality (PIM) and PIM 2 in a Pediatric Intensive Care Unit in a Middle-Income Country. In: 5th World Congress on Pediatric Critical Care, 2007.Pediatric Critical Care Medicine. Baltimore: Lippincott Willians and Wilkins. 2007(8) A71-.

5. Mangia CMF, Nakano EY, PEREIRA. Carlos Alberto de Bragança. Brazilian Pediatric Prognostic Model for Critical Illness. In: EBEB X - $10^{\circ}$ Encontro Brasileiro de Estatística Bayesiana, 2010, Rio de Janeiro. EBEB X - $10^{\circ}$ Encontro Brasileiro de Estatística Bayesiana; 2010.

6. WHO-UNICEF. Declaração Mundial Sobre a Sobrevivência, a Proteção e o Desenvolvimento das Crianças nos Anos 90.http://www.unicef.org/brazil/summit2.htm.

7. Pollack MM, Ruttimann UE, Getson PR: Pediatric Risk of Mortality (PRISM) score. Crit Care Med. 1988; 16:1110-1116.

8. Wells M, Riera-Fanego JF, Luyt DK. Poor discriminatory performance of the Pediatric Risk of Mortality (PRISM) score in a South African intensive care unit. Crit Care Med. 1996; 24(9): 1507-1513.

9. Pollack MM, Patel KM, Ruttimann UE. PRISM III: An updated pediatric risk of mortality score. Crit Care Med .1996; 24:743-752.

10. Knaus WA, Wagner DP, Draper EA, Zimmerman JE, Bergner M, Bastos PG, Sirio CA, Murphy DJ, Lotring $\mathrm{T}$, Damiano A, Harrell Jr FE. The APACHE III prognostic system: risk prediction of hospital mortality for critically III hospitalized adults. Chest. 1991 Dec 1;100(6):1619-36.

11. Le Gall JR, Lemeshow S, Saulnier F. A new simplified acute physiology score (SAPS II) based on a European/North American multicenter study. Jama. 1993 Dec 22;270(24):2957-63.

12. Lemeshow S, Teres D, Klar J, Avrunin JS, Gehlbach SH, Rapoport J. Mortality Probability Models (MPM II) based on an international cohort of intensive care unit patients. Jama. 1993 Nov 24;270(20):2478-86.

13. Shann F, Pearson G, Slater A, Wilkinson K. Paediatric index of mortality (PIM): a mortality prediction model for children in intensive care. Intensive care medicine. 1997 Feb 1;23(2):201-7.

14. Knaus WA, Draper EA, Wagner DP, Zimmerman JE. APACHE II: a severity of disease classification system. Critical care medicine. 1985 Oct 1;13(10):818-29.

15. Iezzoni LI, Heeren T, Foley SM, Daley J, Hughes J, Coffman GA. Chronic conditions and risk of inhospital death. Health services research. 1994 Oct;29(4):435.

16. Pollack MM, Patel KM, Ruttimann U, Cuerdon T. Frequency of variable measurement in 16 pediatric intensive care units: influence on accuracy and potential for bias in severity of illness assessment. Critical care medicine. 1996 Jan 1;24(1):74-7.

17. Pittet D, Thiévent B, Wenzel RP, Li N, Gurman G, Suter PM. Importance of pre-existing comorbidities for prognosis of septicemia in critically ill patients. Intensive care medicine. 1993 May 1;19(5):265-72.

18. Knaus WA, Wagner DP, Zimmerman JE, Draper EA. Variations in mortality and length of stay in intensive care units. Annals of Internal Medicine. 1993 May 15;118(10):753-61. 
19. Brazilian Ministry of Healthy - DATASUS [database on the Internet].[cited 1999 Oct 1]. Available from: http://tabnet.datasus.gov.br/cgi/ deftohtm.exe? sih/cnv/miuf .def.

20. Kollef MH, Schuster DP. Predicting intensive care unit outcome with scoring systems: Underlying concepts and principles. Critical care clinics. 1994 Jan 1;10(1):1-8.

21. Concato J, Feinstein AR, Holford TR. The risk of determining risk with multivariable models. Annals of internal medicine. 1993 Feb 1;118(3):201-10.

22. Lemeshow S, Le JR. Modeling the severity of illness of ICU patients: a systems update. Jama. 1994 Oct 5;272(13):1049-55.

23. Barlow BE and Pereira CA de B. Medical diagnosis using influence diagrams. Networks. 1990;20(1):565-577.

24. Pereira CA de B and Pericchi P. Analysis of diagnosability. J Royall Statistical Society C (Applied Statistics). 1990; 39(2):189-204.

25. Marcin JP and Pollack MM. Review of the methodologies and applications of scoring systems in neonatal and pediatric intensive care. Ped Crit Care Med. 2000; 1:20-7.

26. Van Keulen JG, Gemke RJBJ and Polderman KH. Effect of training and strict guidelines on the reliability of risk adjustment systems in pediatric intensive care. Intensive Care Med. 2005; 31:12291234.

27. Curtis JR, Rubenfeld GD and Hudson LD. Training pulmonary and critical care physicians in outcome research. Should we take the challenge? Am J Resp Crit Care Med. 1998; 157:1012-1015.
28. Marcin JP, Pollack MM, Patel KM. Decision support issues using physiology-based score. Intensive Care Med. 1998; 24(12): 1299 -1304.

29. Daly K, Beale R and Chang RWS. Reduction in mortality after inappropriate early discharge from intensive care unit: logistic regression triage model. BMJ. 2001; 322:1274-1276.

30. Lucas P. Bayesian analysis, pattern analysis, and data mining in health care. Curr Opin Crit Care. 2004; 10:399-403.

31. Marcin JP, Pollack MM, Patel KM, Ruttimann UE. Combining physician's subjective and physiologybased objective mortality risk predictions. Critical care medicine. 2000 Aug 1;28(8):2984-91.

32. Thukral A, Lodha R, Irshad M and Arora NK. Performance of Pediatric Risk of Mortality (PRISM), Pediatric Index of Mortality (PIM) and PIM 2 in a pediatric intensive care unit in a developing country. Pediatr Crit Care Med. 2006;7(4): 356-361.

33. Van Keulen JG, Polderman KH, Gemke RJBJ. Reliability of PRISM and PIM scores in paediatric intensive care. Arch Dis Child. 2005; 90:211-214.

34. Higgins TL, McGee WT, Steingrub JS. Early indicators of prolonged intensive care unit stay: Impact of illness and pre-intensive care unit lengh of stay. Crit Care Med. 2003; 31:45-51.

35. Marik PE, Varon J. Severity scoring and oucome assessment. Crit Care Clin. 1999; 15:633-46.

36. Le Gall JR. The use of severity scores in the intensive care unit. Intensive Care Med. 2005; 31(12):1618-1623.

\section{APPENDIX 1}

\begin{tabular}{|c|c|}
\hline \multicolumn{2}{|c|}{ The values considered worst value in the model developing } \\
\hline Variable & Values \\
\hline Age Group & $<12$ months \\
\hline Medical & No surgical patients \\
\hline Comorbidity & $\begin{array}{l}\text { Congenital cardiopathy, cancer, chronic kidney failure, chronic liver failure, } \\
\text { genetic syndrome, acquired immunodeficiency. }\end{array}$ \\
\hline Pupil reactions & $\begin{array}{l}\text { Worst situation: both fixed, miosis bilateral and few reactions, pinpoint and no } \\
\text { reactive, one fixed and one reactive. }\end{array}$ \\
\hline Glasgow coma scale & Glasgow $\leq 10$ in the metabolic coma \\
\hline Mechanical ventilation & In the first $24 \mathrm{hr}$. \\
\hline Vasoactive drugs & In the first $24 \mathrm{hr}$. \\
\hline $\begin{array}{l}\text { Systolic blood pressure }(\mathrm{mmHg}) \\
<12 \text { months } \\
12 \text { to } 59 \text { months } \\
60 \text { to } 119 \text { months } \\
120 \text { to } 179 \text { months } \\
>180 \text { months }\end{array}$ & $\begin{array}{l}\leq 70 \mathrm{mmHg} \\
\leq 70 \mathrm{mmHg} \\
\leq 70 \mathrm{mmHg} \\
\leq 90 \mathrm{mmHg} \\
\leq 90 \mathrm{mmHg}\end{array}$ \\
\hline Temperature (To. C) & $\geq 38^{\circ} \mathrm{C}$ \\
\hline Diuresis $(\mathrm{ml} / \mathrm{kg} / \mathrm{hr})$ & $<1.0 \mathrm{ml} / \mathrm{kg} / \mathrm{hr}$ \\
\hline Saturation $\mathrm{O} 2$ & $<90 \%$ \\
\hline Coagulation (sec) & APTT $(\mathrm{sec}) 1.5$ times up to reference value or $>52.5 \mathrm{sec}$. \\
\hline Sodium $(\mathrm{meq} / \mathrm{l})$ & $\leq 130$ \\
\hline Potasium (meq/l) & $\leq 3.0$ \\
\hline Glucose $(\mathrm{mg} / \mathrm{dL})$ & $\geq 150$ \\
\hline LOS before PICU & $\geq 8$ days \\
\hline
\end{tabular}


Mangia CMF et al., SAS J Med, August, 2020; 6(8): 182-191

\section{APPENDIX 2}

\section{Sample calculation of score}

Consider a child who is admitted to intensive care with the following data: age 16 months ( age group $\leq 12$ months $=$ no $=0)$, severe sepsis $($ medical $=$ yes $=1)$, hasn't comorbities $($ no $=0)$, receiving vasoactive drugs (yes $=1$ ), is ventilated immediately after admission ( mechanical ventilation $=$ yes $=1)$, has a systolic blood pressure (SBP) of $63 \mathrm{mmHg}$ ( $\mathrm{SBP}<70 \mathrm{mmHg}$ considering age group $=$ yes $=1$ temperature of $38^{\circ}$.C ( Temp $\geq 38^{\circ} . \mathrm{C}=$ yes=1), diuresis of $0.8 \mathrm{ml} / \mathrm{kg} / \mathrm{hr}$ (diuresis $\leq 1.0 \mathrm{ml} / \mathrm{kg} / \mathrm{hr}=$ yes $=1)$, ATTP of $105 \mathrm{sec}$. ( ATTP $\geq 52.5 \mathrm{sec}=$ yes $=1)$, potassium of $2.0 \mathrm{mEq} / \mathrm{L}(\mathrm{K}$ $\leq 3 \mathrm{mEq} / \mathrm{L}=$ yes $=1)$, sodium of $129 \mathrm{mEq} / \mathrm{L}(\mathrm{Na} \leq 130$ $\mathrm{mEq} / \mathrm{L}=$ yes $=1$ ), $\mathrm{SatO}_{2}$ of $89 \%$ ( Saturation arterial $\mathrm{O}_{2}$ $<90 \%=$ yes $=1$ ), normal pupils $($ no $=0)$ and glasgow coma score $>10($ no $=0)$, waited in the emergency room for a bed in the ICU for 6 days (LOS before PICU $>8$ days $=$ no $=0$ ).

Using the coefficients in Table 2 and 3 we have final model derived from the first regression and conditional regression, the BrRISM logit for:

First regression is $=(1.057 * 1)+(1.179 * 0)$

$+(0.569 * 1)+(2.006 * 0)+(0.774 * 0)+(0.541 * 1)+(1.014 * 1)+$
$(0.850 * 1)+(0.789 * 1)+(1.047 * 1)+(1.059 * 1+(-5.603)=$ 1.323

Conditional regression is $=(1.203 * 0)+(0.648 * 1)$ $+(1.660 * 0)+(-0.876 * 1)+(0.873 * 1)+(1.699 * 0)+\quad(0.713 * 1)$ $+(1.701 * 1)+(-4.206)=-1.793$

The logit should be converted to the predicted probability of death.

The predicted probability of death first regression $)=$ $\mathrm{e}^{\text {logit }} /\left(1+\mathrm{e}^{\text {logit }}\right)=\mathrm{e}^{1.323} /\left(1+\mathrm{e}^{1.323}\right)=0.78968$

The predicted probability of death in the PICU $($ conditional regression $)=\mathrm{e}^{\operatorname{logit}} /\left(1+\mathrm{e}^{\operatorname{logit}}\right)=\mathrm{e}^{-1.793} /\left(1+\mathrm{e}^{-}\right.$ $\left.{ }^{1.793}\right)=0.142705$

After this step, the probabilities should be used for calculating de index of severity-of-illness = $\left(2^{1 / 2}+1\right) \operatorname{Pr}(\mathrm{U})-\left(2^{1 / 2}\right) \operatorname{Pr}(\mathrm{H})=\left[\left(2^{1 / 2}+1\right) * 0.78968\right]-$ $\left[\left(2^{1 / 2}\right) * 0.142705=0.65\right.$ ( high risk index $\geq 0.3058$ (table 4). In the table 5, the high-risk patient is in the column 3 the a priori probability of death in PICU was $10 \%$ and after adjustment the probability of death in PICU was estimated in $43 \%$ (a posteriori probability). Apriori probability for hospital death after PICU stay was 5\% after adjustment the probability is $10.5 \%$. Apriori probability for survival after hospital stay was $85 \%$ and a posteriori $46 \%$. 